\title{
Honorários de um cirurgião na Justiça (Vila Boa de Goiás, 1801)
}

\author{
A surgeon's fees in court \\ (Vila Boa de Goiás, 1801)
}

Lena Castello Branco Ferreira de Freitas

Professora titular aposentada/ Universidade Federal de Goiás. Caixa Postal 101

75380-000 - Trindade - GO - Brasil

lenacastelo@uol.com.br
FREITAS, Lena Castello Branco Ferreira de. Honorários de um cirurgião na justiça (Vila Boa de Goiás, 1801). História, Ciências, Saúde Manguinhos, Rio de Janeiro, v.19, supl., dez. 2012, p.299-308.

\section{Resumo}

Estuda-se a ação judicial de cobrança de honorários, proposta em Vila Boa de Goiás (1801), pelo cirurgião-mor André Villela da Cunha Roza, sendo ré a senhora Joanna da Fonseca Coutinha. Enfoca-se a prestação de assistência médica aos escravos, a escassez e o encarecimento deles, a precariedade da formação de físicos e cirurgiões, assim como problemas éticos na cobrança dos honorários em questão.

Palavras-chave: honorários médicos; escravos; história de Goiás (século XVIII); Brasil.

\section{Abstract}

The article explores the lawsuit brought by Surgeon-Major André Villela da Cunha Roza against Joanna da Fonseca Coutinha in Vila Boa de Goiás in 1801 to recover fees for his services. It examines the health care rendered to slaves, the scarcity and rising prices of these captives, the precarious training received by doctores and surgeons, and the ethical issues entailed in charging the fees in question.

Keywords: medical fees; slaves; history of Goiás; Brazil (eighteenth century). 
To final do século XVIII, Vila Boa de Goiás era capital da capitania do mesmo nome e 1 porta de entrada do vasto sertão que se estendia além do meridiano de Tordesilhas. Originária de arraiais que surgiram com o achamento de ouro no rio Vermelho, conheceu breve período de fastígio e crescimento urbano, logo interrompido pelo esgotamento das minas. A despeito do empobrecimento, continuou a ser a sede do governo até 1935, quando a capital do estado foi transferida para Goiânia.

Repetia-se, ali, a dicotomia própria da sociedade colonial brasileira: uma população composta de livres/brancos e escravos/negros e mestiços. Para uns e outros, eram precários os serviços de assistência médico-hospitalar; pouquíssimos físicos (médicos) e cirurgiões atuaram naquela remota região.

O documento que ora se estuda enfeixa manuscritos avulsos, de natureza oficial, existentes no Arquivo da Fundação Frei Simão Dorvi da Cidade de Goiás (antiga Vila Boa). Consta de dez páginas íntegras, escritas em letra cursiva razoavelmente legível; algumas poucas palavras e rubricas são indecifráveis. Trata-se de ação judicial movida pelo cirurgiãomor André Villela da Cunha Roza, relativa à cobrança de honorários devidos pela prestação de assistência médica a um escravo da senhora Joanna da Fonseca Coutinha. Os autos datam de 1801. Nessa época, era governador e capitão-general da capitania de Goiás, dom João Manoel de Menezes (1800-1804). Nos manuscritos, o vocabulário empregado, bem como fatos e ideias referidos, insere-se no contexto da época. Os documentos são interessantes para o estudo da história social, com desdobramentos na história da medicina, porquanto suscitam questões pertinentes a doenças, receituário e medicamentos da época, bem como à ética profissional e às relações entre senhores e escravos.

\section{Apresentação do documento}

Aos 20 dias do mês de abril de 1801, em Vila Boa de Goiás, o cirurgião-mor André Villela da Cunha e Roza (como justificante) ajuizou ação sumária de cobrança de dívida contra Joanna da Fonseca Coutinha (como justificada), relativa a honorários explicitados na "conta que me deve e já dei (Ação, 1801). ${ }^{1}$

O autor apresenta requerimento em que diz ser "Cirurgião aprovado por Sua Mag[estad]e. q. D[eus] hage" 2 - e, como tal, "assiste a todos os infermos ... assim p[ar]a. cazo cyrurgico, como de Medicina, pelos não haver [médicos], e sempre com boa aceitação de todos". Acrescenta que foi chamado pela justificada - referida ora pelo nome de Joanna da Fonseca Coutinha, ora pelo de Joanna Cardoza - "para lhe curar a hum seu escravo molato". Deu assistência ao enfermo e, a pedido da senhora do paciente, "comprou e manipulou todos os remédios que lhe forão precizos", os quais relaciona na conta "que junta por extenço".

Esclarece que "a dita conta importa, assim de vizitas como de Remédios [em] 7/8 e 3/4", ou seja, sete oitavas de ouro e três quartas partes, das quais a justificada pagara uma

\footnotetext{
${ }^{1}$ Nas transcrições, é respeitada a grafia original; completaram-se algumas palavras abreviadas, cf. indicado.

2 O nome do justificante não consta da "Tabela I. Cirurgiões na Capitania de Goiás (1774-1831)" elaborada por Karasch; em data aproximada (1798), o único mencionado é Alexandre Pereira de São Payo (Karasch, 1999, p.43).
} 
fração. Cientificada, a senhora Joanna reconheceu a dívida e "pedio espera (prazo) por duas vezes, confeçando sempre a Conta". O justificante "pôs em fé" que logo receberia o que lhe era devido, pelo que não prosseguiu de imediato na cobrança.

Quanto ao paciente, diz o justificante que "sarou, ainda que não perfeitamente, p. q. carecia [ser] mais Medicado ..., no que a Justificada não conveyo (não concordou), p[ar]a não gastar". Estando convalescente o escravo, foi o cirurgião-mor informado pela senhora Joanna "que o dito rapaz infermo estava bem oprimido (afetado) de lombrigas". Respondeulhe que "comprasse os remédios, que lhe insinuou (receitou) para o Curar, o que ella não fez por mizera". Passado algum tempo "faleceu o d[it]o Molatinho de morte repentina, no que o Justif[icante não teve culpa".

Prossegue, lembrando ser "certo q. aos Médicos e Cyrurgioens se lhes deve pagar o seu premio (remuneração) posto q[u]e morra o infermo". E mais: afirma que a justificada é "custumada a negar o devido premio aos Cyrurgioens q. lhe assistem aos seus infermos", tal como sucedera anteriormente a outro médico, o doutor Placido, "e ao mesmo Justif[icant]e, pela cura que lhe fez ao seu crioulo Franco". Em tais casos, para receberem os honorários, "a ambos [os cirurgiões] foi precizo usar dos termos judiciais". Sobre si mesmo, lembra o justificante que é pessoa "de conhecida e notoria verdade e bem acreditado na sua Arte", e conclui que a justificada deve ser condenada a pagar "o principal [da dívida] e custas".

A leitura do documento parcialmente transcrito suscita questões interessantes. A dívida cobrada diz respeito a honorários devidos por assistência médica prestada a um escravo, a pedido de sua senhora.

Escravos constituíam-se em bens semoventes de alto valor. Em Goiás, em meados do século XVIII, o preço de um negro "bem feito, valente e ladino" era de "trezentas oitavas de ouro" (Antonil, 1963, p.75); "uma mulata de partes" podia custar mais que o dobro (Palacin, 1994, p.88, nota 16) - o que, em valores atualizados, corresponderia a 48 mil reais e a cem mil reais respectivamente; lembre-se, entretanto, que, no período colonial, o valor do ouro era bem mais elevado do que hoje.

O paciente atendido pelo cirurgião-mor era "um molato" ou "molatinho": mestiço, portanto, o que permite supor que fosse filho de homem branco - talvez da família de dona Joanna - com escrava. Talvez por esse motivo ela se dispusesse a tratá-lo, desde que cirurgião e remédios não lhe onerassem o orçamento.

Outra hipótese seria a de que dona Joanna fosse uma daquelas senhoras católicas, imbuídas de caridade cristã - que então as havia - empenhadas em minorar os sofrimentos dos pobres. A iniciativa de dar assistência médica aos escravos não lhe era estranha, como relata o cirurgião-mor. Todavia, como não pagasse em dia os honorários dos facultativos, foi cobrada judicialmente repedidas vezes.

Seria ela pessoa de poucas posses? Há indícios de que não o fosse. Nos autos, Joanna da Fonseca Coutinha assina procuração para seu advogado, em letra bem traçada e legível, o que era incomum nas minas de Goyaz, onde escasseavam mulheres alfabetizadas. Esse detalhe sugere pessoa com nível de instrução acima da média, sendo razoável supor que integrasse os estratos privilegiados da sociedade. A própria deferência com que o cirurgiãomor assistiu ao "molatinho" - visitando-o 16 vezes, conforme consta da conta apresentada 
- sugere ser a devedora senhora de elevada posição social, possuidora de bens que garantiam o pagamento das dívidas cobradas.

No final do século XVIII, caiu progressivamente a produção das minas de ouro de Goiás: em 1779, pela primeira vez os quintos reais não chegaram a 15 arrobas (125kg); 25 anos antes, tinham alcançado quarenta arrobas $(600 \mathrm{~kg})$, o que corresponde a três toneladas (3000kg) de ouro extraído e quintado. No governo de dom Tristão da Cunha Menezes (1783-1800), acentua-se o declínio; uma década depois, a arrecadação anual será de apenas duas arrobas e meia (73,5kg) (Palacin, 1994, p.65-66).

São conhecidas as consequências da diminuição da atividade mineratória: empobrecimento geral, ruralização da economia, refluxo dos mineiros e aventureiros que tinham afluído para os arraiais, nas proximidades das minas. A população da capitania, que até então aumentara, estagnou e passou a decrescer: entre 1783 e 1804, caiu em cerca de um quinto (Palacin, 1994, p.70).

No auge da corrida do ouro, mineiros poderosos, senhores de 'grandes fábricas', possuíam 150 a duzentos escravos. Com o esgotamento dos veios, esses potentados seguiram em busca de novos eldorados e levaram consigo seus negros, com o que a presença deles diminuiu em Goiás.

O crescimento vegetativo da população escrava não era suficiente para a reposição dos mortos e dos que saíam da capitania. Nas duras condições de trabalho das minas, os negros morriam cedo; para garantir a mão de obra necessária, os senhores endividavam-se e compravam mais escravos - até que a crise se abateu sobre a capitania, inviabilizando a aquisição de novas peças. O governador e capitão-general dom Luiz de Mascarenhas queixava-se, em 1781, de que havia anos não se importavam escravos por falta de dinheiro. Em Goiás havia, então, 58.829 habitantes; 13 anos depois, em 1804, o total fora reduzido para 50.135; desses, somente 7.273 (6,9\%) viviam em cativeiro.

A escassez fazia com que o valor do escravo se mantivesse elevado - outra explicação possível para o interesse de dona Joanna pela saúde dos seus cativos. Esse cuidado, todavia, não era tão raro quanto se poderia supor, quando se tem em mente a desumanidade inerente ao instituto da escravidão. Assim é que, alguns anos depois, ao ser instalado em Vila Boa de Goiás o Hospital de Caridade São Pedro de Alcântara, muitos pacientes eram escravos, admitidos desde que seus senhores custeassem as despesas (Moraes, 1999, p.139-140). Em verdade, tratava-se antes de zelo pelo patrimônio do que de humanitarismo ou caridade para com o semelhante.

Sabia o justificante, por experiência própria e de um colega, que dona Joanna tinha por hábito não pagar - ou demorar a pagar - os serviços profissionais de assistência aos seus escravos. Não obstante, o doutor André Vilella da Cunha e Roza não se negou a atender o "molatinho" doente, nem a comprar-lhe e aviar-lhe (preparar-lhe) os remédios. Arcou com tais gastos, tendo a promessa da senhora de que "sem falta ... pagava p[e]lo Espírito Santo que passou", ou seja, por ocasião da festa dessa devoção.

Como não cumprisse o prometido, foi enviada a conta a dona Joana; quase quatro meses depois, ser-lhe-ia o documento oficialmente entregue pelo alcaide, o qual atesta que a devedora "não duvidou", ou seja, não contestou o valor cobrado. 
Ao longo do tempo, dona Joanna - não obstante haver prometido "pagar em ouro" amortizou parte da dívida, entregando ao credor oito libras ${ }^{3}$ de toucinho e sete libras de sabão, meio alqueire ${ }^{4}$ de farinha; uma quarta ${ }^{5}$ de arroz limpo e outra de feijão.

Pessoas de prol eram proprietárias de áreas e chácaras na periferia urbana, cultivandoas por seus escravos e prepostos. Possivelmente, era ela uma das 'roceiras' que possuíam propriedades nos arredores de Vila Boa, conforme indicado em documentos que informam o pagamento de dízimos sobre a produção agropastoril. ${ }^{6}$

$\mathrm{Na}$ conta apresentada pelo cirurgião-mor, os valores correspondentes aos gêneros agrícolas, recebidos de dona Joanna em pagamento, somam 1,5 oitava de ouro; comparativamente, era altíssimo o custo dos remédios: um 'cordial'7 é cobrado à razão de três oitavas; uma 'purga de maná', ${ }^{8}$ meia oitava e um quarto; um 'óleo de Morrinhos' custa três quartos, tudo somando três oitavas e três quartos.

Com efeito: os remédios eram caros e raros, sendo muitos deles obtidos pela manipulação de fórmulas. Os ingredientes e produtos químicos básicos - os símiles - vinham de Portugal ou de pontos diversos do continente americano, como a quina, utilizada no combate às febres. O "molatinho" de dona Joanna, "oprimido de lombrigas", era portador de um dos males mais comuns entre os escravos: a verminose ou amarelão (ancilostomíase), para cujo tratamento recomendava-se, entre outras 'meizinhas', o chá de raiz de maracujá (Salles, 1999, p.75).

O remanescente da conta a receber somava seis oitavas e um quarto. Na capitania, era crônica a falta de moeda corrente, substituída pela oitava de ouro em pó (3586g) que, durante todo o período colonial, esteve cotada a $1 \$ 500$ (um mil e quinhentos réis). Para efeito de comparação, veja-se o salário anual do cirurgião-boticário do Hospital de Caridade São Pedro de Alcântara: 144\$000: (Freitas, 2004, p.213), o que correspondia a $12 \$ 000$ por mês (oito oitavas de ouro). Essa quantia representava pouco mais do que a conta cobrada judicialmente, no valor de sete oitavas e três quartos.

Chama a atenção a insistência - revestida de certo tom desafiador - com que o cirurgiãomor Villela se exime da responsabilidade da morte do "molatinho", atribuindo-a a dona Joanna e afirmando que a ela "não conveyo ... por mizera" (avareza) gastar com remédios. Talvez fosse a devedora figura conhecida como avarenta, talvez como devedora contumaz. Do ponto de vista ético-profissional, até que ponto seria aceitável tal postura do cirurgiãomor?

André Villela da Cunha Roza não era físico - designação que se dava ao médico, nos séculos iniciais da colonização. Os 'bacharéis em medicina' estudavam nas universidades

\footnotetext{
${ }^{3}$ Libra: antiga unidade de massa, correspondendo a $550 \mathrm{~g}$.

${ }^{4}$ Alqueire: antiga medida de capacidade para secos e líquidos; em Lisboa, correspondia a 13,8 litros.

${ }^{5}$ Uma quarta corresponde a quarenta litros.

${ }^{6}$ Cf. livros relativos ao pagamento de dízimos em Vila Boa de Goiás, no Museu das Bandeiras, cidade de Goiás.

${ }^{7}$ Cordial: medicamento ou bebida que fortalece ou conforta.

${ }^{8}$ Maná: suco de algumas árvores, principalmente do freixo-da-calábria (Fraxinus excelsior), empregado em medicina como purgante.
} 
europeias. No final do século XVIII, na Universidade de Coimbra - centro de formação das elites do império português -, foram implementadas reformas no ensino que passaram a exigir, para ingresso no curso de medicina, conhecimentos de latim e grego, além de estudos filosóficos e matemáticos (Carvalho, 1978, p.165-167). Com cinco anos de duração, o curso era ministrado em seis cadeiras, sendo o estudante obrigado a praticar em hospitais, sob a orientação de lentes, professores catedráticos de notório saber.

No Brasil, havia poucos físicos; médicos que possuíssem "a ciência e o caráter" geralmente eram "os últimos a se estabelecerem num país relativamente novo", registra Santos Filho (1991, p.63). Na falta deles, atuavam os cirurgiões.

Vista como ofício manual - e, via de consequência, como ofício servil - a cirurgia era considerada indigna dos físicos, sendo exercida por pessoas de baixa extração social. O aprendiz recebia ensinamentos de um cirurgião ou buscava-os em um hospital (Santos Filho, 1991, p.294), submetendo-se posteriormente a exames perante autoridades credenciadas, para obter a 'carta' que lhe permitiria exercer a profissão.

André Villela da Cunha Roza fora aprovado e autorizado a trabalhar como cirurgião; na verdade, exercia integralmente a medicina - segundo afirma - dada a inexistência de físicos em Goiás. Diz-se cirurgião-mor, nome dado ao profissional incorporado aos regimentos das diferentes armas que constituíam o Exército português (Santos Filho, 1991, p.297). O cirurgião-mor não fazia jus à patente militar; era oficial hierarquicamente inferior, abaixo de alferes, sendo invocado pelo seu título profissional.

O justificante exercia a medicina, portanto, de forma empírica e pragmática, faltandolhe a fundamentação filosófica e ética que, desde sempre, preside a formação do médico. Com o objetivo de receber o pagamento de serviços prestados, não o constrangiam escrúpulos ao atribuir à "mizera" (avareza) as decisões da senhora do escravo e imputar-lhe a culpa pela morte do "molatinho", assim eximindo-se de responsabilidade pelo desenlace.

É de supor-se que as afirmações e acusações do cirurgião-mor chegassem ao conhecimento da população, suscitando comentários e gerando mal-estar na própria devedora e entre seus familiares. Em Vila Boa, com pouco mais de três mil habitantes, as novidades eram escassas, e o isolamento em que se vivia contribuía para amplificar as notícias, agilizar os boatos e exacerbar os juízos de valor.

Nos autos, dona Joanna constitui seus procuradores o reverendo doutor Salvador dos Sanctos Baptista Leyte e o advogado alferes Felipe Rodrigues Gamboa. Parece incomum a rapidez com que tramita a ação, o que dá respaldo à suposição de ser a justificada pessoa de relevo na sociedade local. O simples fato de um sacerdote titulado funcionar no processo corrobora a hipótese.

Os autos de cobrança da dívida são protocolados em 20 de abril de 1801; a procuração data de 21 do mesmo mês; em 23, é dada vista do processo ao reverendo, que o devolve dois dias depois. Para evitar comentários maldosos, terá ele aconselhado sua constituinte - de quem possivelmente seria confessor -, a quitar logo a dívida, que era irrecusável?

Certo é que, de maneira surpreendentemente rápida, a ação é encerrada com termo de quitação, datado de 6 de maio de 1801, apenas 17 dias depois de iniciado o feito. No cartório, perante o tabelião e testemunhas, pelo cirurgião-mor André Villela da Cunha Roza foi dito que "de sua livre vontade e sem constrangimento de peçoa alguma dava 
quitação a Justificada Joanna da Fonsequa Coutinha, por estar pago e satisfeito de todo o principal e custas".

Apresentada há mais de dois anos e reconhecida pela devedora, que não a pagou em tempo razoável, a conta estava finalmente quitada, depois de acionada a Justiça, que se mostrou ágil e eficiente em Vila Boa de Goiás, no longínquo alvorecer do século XIX.

\section{REFERÊNCIAS}

AÇÃO.

Ação (ordinária) de artigos justificativos entre partes. O cirurgião-mor André Cilla. Da Cunha e Roza. Justificante. Justificante. Joanna da Fonseca Coutinha. Justificada. Villa Boa de Goiás. Documento avulso manuscrito. (Arquivo da Fundação Frei Simão Dorvi, Cidade de Goiás). 1801.

ANTONIL, André João.

Cultura e opulência no Brasil por suas drogas e minas. Rio de Janeiro: IBGE. 1963.

CARVALHO, Laerte Ramos de.

As reformas pombalinas da instrução pública. São Paulo: EdUSP/Saraiva. 1978.

FREITAS, Lena Castello Branco Ferreira de. Médicos europeus na província de Goiás. In: FREITAS, Lena C.B.F. de. Goiás: história e cultura. Goiânia: Descubra. p.201-230. 2004.

KARASCH, Mary C.

História das doenças e dos cuidados médicos na capitania de Goiás. In: Freitas, Lena C.B.F. de (Org.). Saúde e doenças em Goiás: a medicina possível: uma contribuição para a história da medicina em Goiás. Goiânia: Cegraf/UFG. p.19-62. 1999.

MORAES, Cristina de Cássia Pereira.

O Hospital de Caridade São Pedro de Alcântara e os trabalhadores na cidade de Goiás (1830-1860). In: Freitas, Lena C.B.F. de (Org.). Saúde e doenças em Goiás: a medicina possível: uma contribuição para a história da medicina em Goiás. Goiânia: Cegraf/UFG. p.129-168. 1999.

PALACIN, Luis.

O século do ouro em Goiás (1722-1822): estrutura e conjuntura numa capitania de minas. Goiânia: EdUCG. 1994.

SALLES, Gilka Vasconcelos Ferreira de. Saúde e doenças em Goiás. In: Freitas, Lena C.B.F. de (Org.). Saúde e doenças em Goiás: a medicina possível: uma contribuição para a história da medicina em Goiás. Goiânia: Cegraf/UFG. p.63-128. 1999.

SANTOS FILHO, Lycurgo. História geral da medicina brasileira. $2 \mathrm{v}$. São Paulo: Hucitec/EdUSP. v.1. 1991. 


\section{PROCESSO JUDICIAL DE HONORÁRIOS MÉDICOS}

Folha 4

Por acção sumaria de Artigos justificativos, ou como em direito melhor nome e lugar haja. Diz como Auctor em Juizo o Cyrurgião Mor André Villa da Cunha e Roza contra Joana da Fonseca Coutinha Re citada ...

Que o Justificte. he Cyrurgião aprovado por S. Mage. q. D. hage, e como tal assiste a todos os infermos pa.q. he chamado assim pa. Cazo Cyrurgico, como de Medicina suprindo a falta de Medicos pelos não haver, e Sempre com boa aceitação de todos.

2

Que ao Justificante chamou a Justificada pa. lhe curar ahum seu escravo molato, e com effeito foi e lhe assestio como tão bem a petitorio da Justificada comprou, e manipulou todos os remédios que lhe foram precisos, como se vê da conta q. junta por extenço, que Requeiro se mostre as Mas. pa. q. a ... dela jurem oq. souberem.

3

Que a dita conta importa, assim de vizitas, como de ReMédios $7 / 83 / 4$, p. conta da ql. já pagou a Justificada $1 / 8$ e $1 / 2$ ou o q. melhor constar dos bilhetes que la tem, e falta $6 / 84 \mathrm{q}$. lhe deve pagar com as custas.

4

Que pela dita Conta já o Justificte. mandou citar a Justificada pelo Alcaide Anto. Alz. a qm. pedio espera p. duas vezes confeçando sempre a Conta como o dito declarado ... della, e pr. fim sempre se chegou a Citar, como se vê do Reqo. e Certam. junta q. se pôs em fé, e pq. pedio espera se não continuo.

5

Que o dito infermo sarou ainda q. não perfeitamte. p. q. ainda carecia [ser] mais medicado, no q. a Justificada não conveyo para não gastar, mas sempre se podia tomar qe. passou por esta Va. Repetidas vezes. 
Folha 4 verso

6

Que andando assim o do. infermo na Convalecença, dice a Justificada ao Justife. q. o dito rapaz infermo se achava bem oprimido de lombrigas ao que lhe respondeu comprasse os remedios, que lhe insinuou para o Curar, o que ella não fez por mizera, e passado algum tempo faleceu o do. Mulatinho de morte repentina no que o Justife. não teve culpa sendo Certo q. aos Medicos e Cyrurgioens se lhe deve pagar o seu premio posto q. morra o infermo como se mostrara de dirto.

\section{7}

Que a Justificada he custumada a negar o devido premio aos Cyrurgions q. lhe assistem aos seus infermos Como já negou ao Dr. Plácido, e ao mmo. Justife. em outra occasião pela cura que lhe fez ao seu crioulo Franco., e a ambos lhe foi precizo uzar dos termos judiciaes.

8

Que o Justife. he deconhecida e notória verde. e bem acreditado na sua Arte, e pr. isso senão fosse verde. o q. se allega certamte não viria a Juízo com aprezte. ação. e .... e o justificado o q. baste deve a Justificada ser condenada em principal e custas pois de tudo he

F.P. [Fides publica] 


\section{CÓPIA DA CONTA Q. ME DEVE, E JÁ DEI A SRA. JOANA CARDOZA EM 16 DE JUNHO DE 98}

Cópia da Conta q. me deve, e já dei a Sen ${ }^{\text {ra }}$.Joanna Cardoza em 16 de junho de 98

$\mathrm{P}^{\mathrm{r}}$. cordial $\mathrm{p}^{\mathrm{a}}$. o Seo mulat ${ }^{\mathrm{o}}, \mathrm{p}^{\mathrm{a}}$ o ql. comprei os remédios por me dizer q. sem falta me pagava $\mathrm{p}^{\text {lo }}$ Espirito $\mathrm{S}^{\text {to }}$ que passou e foi justo em $3 / 8$

Da mesma forma hua purga de maná e foi justa em

De Oleo de Morrinhos $\mathrm{p}^{\mathrm{a}}$. omesmo

$$
\begin{gathered}
\frac{}{3 / 8 \text { e } 3 / 4} \\
4 / 8 \\
7 / 8-3 / 4
\end{gathered}
$$

P. 16 vizitas $\mathrm{p}^{\mathrm{a}}$. o mesmo

Soma esta Conta q. ajustou pagar em ouro

Recebi em ...... $\mathrm{p}^{\mathrm{r}}$. bilhetes que lá tem $\mathrm{p}^{\mathrm{a}}$. a conta das vi-

zitas o seg. ${ }^{\mathrm{e}}$

8 L. $^{\text {as }}$ de tou ${ }^{\text {co }} \cdot$ p. $^{\mathrm{r}}$ conta de meia arroba de que foi bilhete $1 / 2$ alqr $^{\mathrm{e}}$. de far ${ }^{\mathrm{a}}$.

7 L. ${ }^{\text {as }}$ de Sabão

1 quarta de arros Limpo

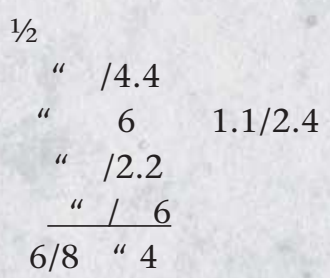

1 quarta de feijão

Hoje, 9 de obr $^{\circ}$. de 1798

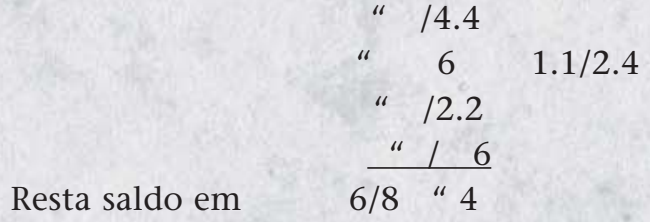

Andre Villela da $C^{a}$. Roza

Declaro q. he serto que aprezentey esta conta a Joana Cardoza Ca não duvidou

o Alcaide

$\mathrm{An}^{\text {to }}$. Alz. Pra 